\title{
A Moment that Goes Beyond Silence: Parents' Lived Experiences of Grief Due to Traumatic Loss in Bataan, Philippines
}

\author{
Jayvie Villazor*1,2 | Rosalito De Guzman ${ }^{1}$
}

\author{
${ }^{1}$ Graduate School, University of Sto. Tomas \\ Manila, Philippines \\ ${ }^{2}$ College of Social and Behavioral Science, \\ Bataan Peninsula State University Balanga, \\ Bataan, Philippines \\ Correspondence \\ *Corresponding Author. \\ Email: jayvie.villazor.gs@ust.edu.ph
}

\begin{abstract}
Existing evidence suggests that adverse effects are numerous after a traumatic event. This research aims to validate that by revealing the lived experiences of trauma survivors over the span of two years. A descriptive phenomenological approach was used to accomplish this goal. For data collection, face-to-face and virtual semistructured interviews were used. The researchers interviewed thirteen parents who had tragically lost a child due to homicide, murder, suicide, or a traffic accident. Four themes appear to emerge, with 17 subthemes. The five subthemes of hurting are behavioral dysfunction, affective destruction, biological pain, cognitive disruption, and interpersonal conflict. Meanwhile, coping has five subthemes: emotion-focused, social interaction-focused, digital-focused, behavior-focused, and cognitive-focused. The growing theme is composed of five subthemes: interpersonal enhancement, life appreciation, spiritual growth, parenting actualization, and insight imparting. The remembering theme is divided into two themes, the presence, and absence of the deceased child. Though limited, this study can nonetheless serve as the country's first to focus on grief by traumatic loss. It will serve as additional knowledge in the fields of psychotraumatology, thanatology, positive psychology, and suicidology in the Philippines. Clinicians and other mental health care providers would benefit from the information based on their own experiences as grieving parents. Additionally, research ideas are provided. Indeed, this paper proves that a survivor can not just experience the negative impacts but also grow personally from one of the most traumatic events in human experience.
\end{abstract}

\section{KEYWORDS:}

grieving, parents, phenomenology, trauma survivor, traumatic loss

\section{1 | INTRODUCTION}

Everyone will inevitably encounter the death of someone dear to them during their lifetime. It varies by category; it could be natural or caused by another unforeseen circumstance. Nonetheless, it is capable of eliciting complex emotional, cognitive, behavioral, and physiological responses in the aftermath of a loved one's death or loss (Worden, 2008). When a parent loses a child, one of the most intense forms of grief occurs. There is compelling evidence that parents' grieving following the death of a child is more acute and lasting than grief following other types of losses (Rafael, 2006). Grief is heightened when a child dies unexpectedly as a result of a traumatic occurrence. According to Henry (2017), "traumatic loss" occurs when a person dies 
unexpectedly or as a result of an accident, suicide, or violence. Additionally, unexpected death was the typical traumatic incident that was almost certainly labeled as the worst traumatic experience of someone's life (Keyes et al., 2014). The reason for this is that the parents will not only have to deal with grief, but also with the interaction of trauma and grief (Rafael, 2006).

There is sufficient research on the overall implications of losing a loved one, but limited research on the specific consequences of losing a beloved person in an unexpected and traumatic occurrence. However, limited studies tend to focus on the short-term and long-term consequences of this type of loss. Keyes et al. (2014) discovered an increased risk of developing multiple psychiatric disorders following the unexpected death of a loved one, including major depressive episodes, panic disorder, posttraumatic stress disorder (PTSD), manic episodes, phobias, alcohol disorders, and generalized anxiety disorder. Furthermore, those who expressed signs of PTSD were more likely to exhibit symptoms of complicated grief (Glad, 2021). When an individual dies as a result of suicide, homicide, violence, or an accident, grief can manifest as post-traumatic stress reactions (Rafael, 2006). Additionally, the individual becomes enraged, seeking explanations for the sudden loss (Brysiewicz, 2007). When a child commits suicide, their parents may experience increased worry, depression, remorse, hopelessness, apathy, and wrath (Lee et al., 2017). When a family member is murdered, it impacts their physical, social, and economic needs (Costa et al., 2017). Meanwhile, deaths caused by vehicular accidents were projected to result in emotional instability, an inability to find meaning, a lack of constructive improvements, and the deterioration of numerous social relationships (Breen, 2006).

The aforementioned consequences demonstrate how delicate and complex it is for impacted people to experience the loss of a loved one due to a traumatic occurrence. As a result, this study conducted in-depth interviews with 13 parents whose children died as a result of events such as suicide, homicide/murder, or vehicular accidents. Their narratives of loss exacerbated by trauma were investigated in detail. The researchers also inquired about how parents in Bataan, Philippines, cope with the following loss.

The researchers chose to focus on grieving parents as they are the ones who are most immediately affected by a child's death. Having a child gives them meaning and happiness. The unconditional love that parents have for their children is unfathomable. Losing a child is so devastating that it may increase a parent's risk of mental illness and death (Li et al., 2003, 2005; Rostila et al., 2012 as cited by Moor Graaf, 2016).

The study's objective was to begin filling in the gaps of grieving holistically by detailing both the parents' unfavorable and positive experiences. Most of the studies on grieving focus on the adverse effects of traumatic loss and grieving, as found in the studies of Keyes et al. (2014), Glad et al. (2021), and Mitchel et al. (2009). These studies have pathologized survivors' grief and suggested that they have negative effects that are addressed as psychiatric problems. Concentrating only on negative results creates an incomplete picture since this body of research overlooks the possible benefits of traumatic loss (Lee et al., 2017). It has been recommended that these traumatic losses can result in beneficial outcomes since individuals are intrinsically inclined to seek positive accommodation due to trauma (Joseph Linley, 2005). This positive change was introduced by Tedeschi and Calhoun (1996) and is labeled as posttraumatic growth. Recent research by Lee et al. (2017), Martineková and Klatt (2017), and Moore et al. (2015) highlights the positive experience and looks for a silver lining in the lives of grieving people. By examining their full experience, the new research provides a more comprehensive and realistic view of grieving parents' traumatic loss. It will equip physicians with precise knowledge, allowing them to avoid immediately pathologizing grief as a mental illness. It can also be noted that it can be a turning point for personal growth and transformation. Clinicians can use the findings of these studies to help them provide mental health services like counseling, psychotherapy, and other individual therapies. It can also serve as the foundation for intervention programs and social support groups for parents who have experienced the loss of a child as a result of traumatic events. Solely, this study answers the central question: "How do parents view and experience grief after the traumatic loss of their child?"

\section{2 | METHOD}

\subsection{Study Design}

The Descriptive Phenomenological Design enables the researchers to maintain the participants' "voice" without abstracting their perspective via analysis (Giorgi Giorgi, 2003 as cited by Meyers, 2019). This design assisted the researchers in extracting the participants' lived experiences of grief thoroughly. 


\section{2 | Participants}

The study's focus is on grieving parents who scored a mean of 4.00 or higher on the Texas Revised Inventory of Grief (TRIG) from various towns in Bataan. A semi-structured interview was conducted with those who unexpectedly lost their children (5-30 years old) between the years 2018-2020, residents of Bataan, and those aged 30 to 60. Meanwhile, parents who are receiving mental health services such as counseling or psychotherapy or are taking psychotropic medications are ineligible to participate in the study. Parents who have been diagnosed with PTSD or other psychological disorders were also excluded. The detailed characteristics of the participants are shown in Table 1

TABLE 1 Demographic Information of Participants

\begin{tabular}{cccccccc}
\hline $\begin{array}{c}\text { Participant } \\
\text { code }\end{array}$ & $\begin{array}{c}\text { Relationship to } \\
\text { the child }\end{array}$ & Age & Civil Status & $\begin{array}{c}\text { Cause of } \\
\text { death of the } \\
\text { Child }\end{array}$ & $\begin{array}{c}\text { Age of the } \\
\text { child upon } \\
\text { Death }\end{array}$ & $\begin{array}{c}\text { Gender of the } \\
\text { Child }\end{array}$ & $\begin{array}{c}\text { Months since } \\
\text { the child } \\
\text { passed away }\end{array}$ \\
\hline Linda & Mother & 48 & Live In & Suicide & 20 & Female & 20 \\
Mary & Mother & 50 & Married & Suicide & 21 & Male & 24 \\
Luis & Father & 51 & Married & Suicide & 21 & Male & 24 \\
Cathy & Mother & 49 & Married & Suicide & 22 & Male & 17 \\
Ronald & Father & 51 & Married & Homicide & 22 & Male & 24 \\
Glenda & Mother & 50 & Married & Homicide & 22 & Male & 24 \\
Jesusana & Mother & 54 & Married & Murder & 25 & Male & 12 \\
Rolando & Father & 52 & Married & Homicide & 22 & Male & 9 \\
Cristina & Mother & 48 & Married & Homicide & 22 & Male & 9 \\
Michelle & Mother & 39 & Widow & Suicide & 15 & Male & 6 \\
Lina & Mother & 44 & Married & Vehicular & 20 & Male & 16 \\
Percival & Father & 39 & Married & Suicident & 16 & Male & 14 \\
Rosie & Mother & 39 & Married & Homicide & 11 & Male & 20 \\
\hline
\end{tabular}

\section{3 | Instrumentation}

The demographic information form consists of two parts. The first part was utilized to obtain the demographic information of the parents. The second part contained questions connected to the deceased child.

TRIG by Faschingbauer (1987) was employed to measure the level of grief of the parents. It is comprised of two scales: TRIGPast and TRIG-Present. However, in this research, only the TRIG-Past scale was used, comprising 13 items. TRIG's internal consistency among grieving parents is $=0.86$ (Martineková Klatt, 2017).

The semi-structured Interview Guide/Interview Protocol guided the researchers to ask questions sequentially, from information about starting the interview up to concluding ideas. The parents were asked the following interview questions: What changes have you experienced as a parent who unexpectedly lost his or her child? What are the difficulties that you experience? How do you cope with the loss?

\section{4 | Data Gathering Procedure}

The gathering of data took place during the first year of the pandemic (September 2020 to December 2020). Through the assistance of the Local Government Unit of Bataan, the researchers sought parents who had recently experienced the unexpected loss of a child. After finding 20 possible participants, the researcher primarily secured written informed consent before utilizing TRIG, which identified the parents' level of grief. After the evaluation of the results, only 13 participants scored highly (4.00 mean and above) in TRIG. They were invited to a semi-structured interview. Prior to the semi-structured interview, participants 
were asked to give informed consent again. The modality of the interview depends on the preference of the selections: face-toface, phone call, or virtual interview via Messenger. The mentioned options were due to the restrictions caused by the pandemic. A semi-structured interview with each parent was recorded using a digital voice recorder to guarantee transcription accuracy and help the researchers focus during the interview process. More so, brief notes were utilized to generate follow-up questions and help in validating responses.

\section{5 | Ethics}

Mainly, the researchers sought the approval of the Ethical Review Board of the University of Sto. Tomas-Graduate School before the commencement of the study. Before the parents participated in the study, the researchers made sure to secure two informed consent forms, which they signed to have their own copy. The parents further affirmed that their involvement was decided according to their own will, and withdrawal from the research was free from penalization. The purpose, risks, and benefits of the study were also discussed. Confidentiality was guaranteed, and the contact information and affiliation of the researcher were provided. All selections received a grocery pack as appreciation for their time, effort, and participation.

\section{6 | Data Anaysis}

The descriptive phenomenology's data analysis followed the seven steps of Colaizzi's (1978 as cited by Sosha, 2012) process for phenomenological data analysis. Initially, recorded interviews of 13 parents were transcribed. Each transcript was reviewed several times for the researcher to obtain clarity and familiarity with the response. Then the significant statements per transcript that pertain to grief were extracted. The statements were recorded on a separate sheet, noting their page and line numbers. Next, the significant statements were thoroughly reviewed to develop their meanings. Then the formulated meanings were sorted according to categories, clusters of themes, and themes. Next, the findings were integrated into exhaustive descriptions of grief. After that, the findings were reduced in which redundant descriptions were eradicated from the overall structure. Finally, to increase the validity and trustworthiness of the findings, the research findings were returned to the participants for review. For a greater understanding of the readers, the verbalizations of the selection were translated from Filipino to English language by an expert in the English language.

\section{3 | RESULTS AND DISCUSSION}

After a thorough analysis of the selection's responses, four interesting themes describing their experience of grief emerged, namely: hurting, coping, growing, and remembering.

\section{1 | Hurting}

Along with a high level of grief, unexpectedly losing a child can also substantially negatively impact the well-being of a parent, especially when the loss is recent and regrets are involved. These negative effects vary for each parent, so that observable symptoms emerge in different aspects, usually after the traumatic event..

\subsection{1 | Behavioral Dysfunction}

Within the first few weeks following the loss, the parents reported a decrease in productivity or doing nothing, which resulted in poor work performance and decreased productivity at home. This includes refusing to do their household chores and a noticeable decrease in their productivity at work, which resulted in either termination or tardiness. Because the study's causes of death were all traumatic, some parents are concerned that the same thing will happen to their remaining children. As a result, parents become overly protective and constantly monitor their children's activities. To make matters worse, the pandemic's restrictions affected them by keeping them at home and limiting their coping options. As some parents have stated:

My husband told me, "Go to work." I replied, "I really don't want to." Why are you forcing me? "I was then fired from my job.(Mary) 
When our youngest child leaves, I will look for him because I am scared. It was as if I had a fear. I'm afraid of not seeing my son again. (Cathy)

I couldn't help it, but before, I really couldn't move. It was like I was always inside our home alone. (Glenda)

It was more difficult during the first lockdown. Schooling has stopped. I work there. We are always at home. It was more painful because I missed their presence, but they were no longer there. (Rosie)

\subsection{2 | Emotional Distress}

After the traumatic loss, waves of emotions have been uncontrollable, such as bouts of crying in secret, mood swings, and fits of anger. Sadness was evident and persistent, especially during the nighttime when they were alone and idle. Overwhelming guilt and self-blame were the initial responses of the parents who lost their children to suicide. It is also accompanied by regrets about the mentality that their children were very young and capable of achieving numerous milestones in the future. They wished to utter words of affirmation toward their children. Also, they were asking their child about a lot of things connected to the loss. Shields et al. (2017) agreed that guilt and self-blame were the few primary responses of mothers who lost their children by suicide. As verbalized by the parents:

Emotionally, I'm just crying in the bedroom, so I won't show it to my youngest child. (Jesusana)

I have a lot of what ifs, self-blame and regrets. How I wish I was there during her difficult situation. (Linda)

\subsection{3 | Biological Pain}

It's like you're hurting yourself. If possible, you wouldn't take him out of your sight If only I knew that it would happen. I shouldn't have let him go home. I should have just left him there. No one else is to be blamed but myself.(Mary)

It is common for grieving parents to have numerous complaints about their physiological well-being: loss of appetite for food that results in weight loss, overeating, hypertension, difficulties sleeping, breathing difficulties, bouts of dizziness, lightheadedness, fever, cough, fatigue, low energy, and palpitations. Some of the physiological changes reported by grieving parents are supported by Buckley et al. (2012). It includes an increase in stress, changes in sleep patterns, and hemodynamic changes such as heart rate and blood pressure. But according to them, it is transitory, especially after some months. As verbalized by some parents:

At first it was hard; it was hard to eat, and I couldn't sleep. Even now, I still wake up suddenly in the middle of the night. I can't sleep. (Lina)

My sugar and cholesterol were elevated because of stress eating due to loss. (Rosie)

\subsection{4 | Cognitive Disruption}

Certain parents lose track of little events that occur in day-to-day circumstances. They, too, paid close attention to items and other aspects. They were mostly muted and stunned over the first few months following the tragic event. More specifically, their imagination was concentrated on hearing their children's voices and seeing their faces. Suicidal thoughts were, by far, the most difficult response to child loss. Some parents expressed a desire to commit suicide, believing that doing so would alleviate the unexplained suffering they were experiencing. Additionally, the limits imposed by the pandemic made some parents more preoccupied with the loss. Due to their confinement to their homes and restricted activities. As several of them remembered:

Sometimes that's what I tell others; sometimes I think of just dying. I wonder why my son's life is like that. (Michelle)

Sometimes it's just my imagination, that I hear her voice 'Mama.' When that thing happened, I just told myself that it was only my imagination. (Lina) 
Not able to perform my job during the pandemic is difficult. You have no source of income and preoccupied of the loss.(Ronald)

\subsection{5 | Social Withdrawal}

It stands to reason that some of the parents interviewed admitted to feeling compelled to isolate themselves following the traumatic event. They began to move in opposition to others and lost interest in social gatherings and interactions during the first few months. Some of them even lost the courage to go out and talk to their neighbors, as they had done before the unexpected loss. Moreover, some of the parents were forced to withdraw socially due to the restrictions imposed by the pandemic. As mentioned by a parent:

My family let me suffered alone. They do not let me grieve from our home. (Michelle)

I feel like I don't care much about people anymore because I was hurt by what my son did. Because I thought he was going to make our lives better, but he didn't. (Ronald)

It so hard for us to go out and see our relatives and other friends during the pandemic. (Rosie)

\section{2 | Coping}

Adjustment in grieving is a dynamic process (Ross et al., 2018). This is the theme's fundamental concept. After a period of mourning, the parents adjust to life without their deceased child. They develop a variety of coping methods in order to adapt to and survive their current predicament. Though these coping mechanisms do not always guarantee that parents will grieve productively and positively, the primary goal is to alleviate the parents' pain and to assist them in getting by day after day until they adjust sufficiently and learn to live with the empty space that their child once occupied. The parents' coping mechanisms were both positive and negative in nature. Positive because some coping mechanisms entailed by them were beneficial because they let them cope with the adverse effects of grief effectively. Meanwhile, it is coined as "negative" because certain coping methods tend to exacerbate the existing negative impacts of loss.

\subsection{1 | Emotion-focused Coping}

Parents who took part in this study expressed how using emotions as a coping mechanism helped them through their grieving process. Release of negative emotions, such as crying, has aided them and continues to aid them in coping with the heaviness of their grieving experience. As shared by a parent:

Of course, you can't get rid of the one you're crying for, talk to him (deceased child), because when I've already poured myself out in crying, I feel relieved. (Jesusana)

\subsection{2 | Social Interaction Focused Coping}

Another coping mechanism that focuses on social interaction is the involvement of others in the parents' grieving process. Following a closer look at the coping style described by the parents in the interview, it was discovered that it could be both positive and negative. It is encouraging that most parents devote their time and energy to caring for their remaining family members and spending time with friends in order to heal from the loss of their child (Cao et al., 2018). Other parents, while negative, relied on blaming the death on others and moving against them to cope with the traumatic or unexpected loss. As the parents openly stated:

We did not let the friends of my child stay for up to 40 days. It's okay for us to feed many people, as long as they are here and become our comfort. (Cristina)

I don't usually talk to my family because they are responsible for my daughter's unfortunate situation. (Linda) 


\subsection{3 | Digital-focused Coping}

Meanwhile, digital-focused coping helped the parents by temporarily distracting them from the pain of their child's tragic death. The Gamba (2016) study strengthened this coping mechanism; numerous websites and social networking sites offer advice on coping with loss, including sites for support, sharing experiences, and expressing grief. However, this coping strategy may not be appropriate for parents who frequently use these platforms. As mentioned by a parent:

Until now, we have not really recovered. We are looking for him from time to time. One night, I learned to use Facebook and YouTube on our two cellphones. The two cellphones were getting battery exhausted because I couldn't sleep. I'm using YouTube to entertain myself until I fall asleep. Until now, I have not been able to stop this practice. (Percieval)

\subsection{4 | Cognitive-focused Coping}

Unexpected child death has a deleterious effect on parents' perceptions of the world, even more so when the traumatic event occurs recently. As a result, some of them admit to diverting their minds in order to deal with the agony of child loss in a productive manner. The parents sought acceptance one day at a time. Regrettably, it is inflicted on oneself with the knowledge that this is their only hope of recovery. As one parent expressed:

I just think of something else, my other children. So when I know I'm going to feel down, I shift my thinking to them and other things. Focusing on the loss will accumulate resentment, and that's on me. (Luis).

\subsection{5 | Behavior-focused Coping}

Even though grieving parents face similar losses, the length of adjustment for each of them varies. Much more, their approach to grief is distinct. Behavior-focused coping elaborates on the positive behavioral changes that some parents undergo in order to recover from the loss of their child. Parents become more productive, pursue new interests, and devote time to self-care. As uttered by a parent:

I took a month's leave from work. Then after that, I went back to work because that's my only hobby now and I won't be able to think about the loss. So I just go to work and divert my attention. (Rosie)

I'm trying to entertain myself, early in the morning I'm starting to ride the tricycle. (Rolando)

\section{3 | Growing}

Interestingly, the findings show that parents have a natural propensity for positive changes after they have adjusted to their loss. These personal enhancements were elaborated on under the growing theme. Though it was clear from the parents' responses that grief does not go away completely, spending enough time with this experience resulted in noticeable positive changes in them.

\subsection{1 | Interpersonal Enhancement}

Improved social interaction as a result of realizing that their remaining family members still rely on them for strength and support. They realized that interpersonal relationships are critical for recovery, which resulted in a higher quality of life for their family. The traumatic experience inspired them to make new and more memories with their loved ones. This finding was supported by Lee et al. (2017), who discovered that warm and intimate relationships emerged following the suicide death of a loved one. According to a parent:

Right now, I'm more understanding of my daughter. I have also become more considerate of other people. I value the people around me, especially the people who love me. (Rosie)

\subsection{2 | Life Appreciation}

They began to realize that life is finite and that death is unpredictable, prompting them to improve the quality of the new life they were given after the death of their child. They were able to rebuild their perceptions and perspectives on life, death, and 
the world. For them, life is short and uncertain, so make the most of it by being grateful for the opportunity to be alive and spending it with those you love and care about (Moore et al., 2015). According to a parent:

I only have a few years left in this world, so why shouldn't I enjoy it with my family? I don't need money; I don't need a job. What I need is my family. It's not that I don't need money literally, but family is always there and no amount of money will equal it. (Mary)

\subsection{3 | Spiritual Growth}

Because spirituality or religiosity is incorporated into coping skills (Bray, 2013), many parents find it useful in solidifying their beliefs and strengthening their relationship with a higher being. God provided them with the strength, hope, and courage they needed to move forward. And when no one else could console them, God provided solace (Henry, 2017). He stated that a violent and traumatic death increases the spirituality and growth of the bereaved individual. As described by a parent:

Those trials that have just passed, I just entrusted them to God. Whether I have doubts about myself, I'm still focusing on him. (Cathy)

\subsection{4 | Parenting Actualization}

Consider how many realizations parents have gained as a result of the death of their child. For example, one of them discussed the flaws inherent in being a parent or guardian of one's children. They acknowledged that they had made mistakes in the past and that the death of their child had taught them not to repeat them. Parents (particularly those who have lost a child to suicide) were keen to improve their parenting style for their remaining children and to boost their enthusiasm at work. Even more so, as several parents have freely shared:

Parents need to engage with their children when already observed to be differently quiet and ask if there is any problem that they want to talk about. As a parent, getting mad is not always the way to go. You should talk and listen to them instead. (Luis)

\subsection{5 | Insight Imparting}

The anguish of losing a child in a tragic and unexpected accident is something that no parent deserves to go through. The knowledge gained by a parent as a result of this loss gave them a sense of purpose to share and counsel others who have suffered a similar loss. Dansart (2016) bolstered this sub-theme by demonstrating how survivors are reclaiming their lives through their commitment to a cause that assists others in overcoming their traumatic experiences. As some of them have explained:

That is quite different, really. That is why I told other youth in our area because my son had friends there. I tell them, "Don't resent your parents if you are being reprimanded. They just love you, that's why." I constantly tell this to all the young people in our place. (Mary)

\section{4 | Remembering}

Unlike other emotions, grief does not pass away after a period of time. It lingers within the individual and occasionally manifests in waves. This final theme was developed to articulate the parents' description of how grief continues to remind them of their deceased child. This theme encompasses both positive and negative memories associated with their child. The presence subtheme evoked primarily positive memories, whereas the absence sub-theme evoked mostly negative and painful memories. And regardless of how long ago their departure occurred, their children are all still alive in their hearts and minds through memories.

\subsection{1 | Presence}

It is natural for parents to remember their deceased children while they are still alive. This includes the personality, habits, and daily routines of the child. Whether the loss was recent or not, these memories surface throughout the grieving process. As one 
parent described a memory of her deceased child:

He always tells us that he loves us very much. That's what he always tells us. Then he even told us, whenever I could think of him, he would tell me 'I'm going to graduate, I'm going to America!" (Mary)

\subsection{2 | Absence}

One of the most difficult aspects of grieving is the longing that comes after death. The heaviest pain, according to some parents, was attending their own child's wake and burial. This type of longing persists throughout the grieving process, even to the present day. Memories of what happened can be triggered by even minor events, such as being in the same location where the traumatic event occurred. As stated by some parents:

I remember him! Everything that happens is playing back in my mind. It keeps on coming back, especially during occasions.. All his friends and cousins are here. Then they will put the picture of him in the middle while eating. (Christina)

\section{I saw him like that, hanging on his knees. I removed the rope, but I couldn't remove him. (Mary)}

When it comes to research, grief is one of the most delicate constructs. It is an experience that not everyone who has it can talk about with such ease. In this study, we discovered that the 13 trauma survivors selected suffered from the negative effects of grieving. This is similar to the findings of Keyes et al. (2014), Glad (2021), and Mitchel et al. (2009): They experience physical symptoms like heart palpitations, sweating, or hyperventilating, changing their personal routine to avoid reminders of the event, distorted feelings of guilt, blaming themselves, negative thoughts, anxiety, persistent sadness, and difficulties in coping. The negative effects of loss were visible in the parents' behavioral, cognitive, emotional, biological, and social aspects.

More so, grieving parents were particularly affected by the pandemic's adverse effects. Some of them were stuck in their homes, where they mostly remember their children. They have limited access to going outside to see their social support, such as other relatives and friends. It is an important finding that clinicians and other mental health professionals should investigate and explore. The grief experienced prior to the pandemic is distinct from the grief experienced during the pandemic. Parents do not have enough time to grieve, especially those who lost their children after the pandemic began in March 2020. Many restrictions imposed by the government limit their resources and ways of dealing with grief. Corpuz (2021) stated that during their grieving, the support of traditional social, cultural, and religious rituals was diminished.

Also, grieving parents are part of a high-risk population that is at risk of suicide. The current study confirmed this, particularly during the first few weeks after the loss. As Lee et al. (2017) mentioned, this is a critical finding that mental health professionals must address. They could help by assisting the grieving parents in reconstructing their memories in the face of loss and assisting them in creating a positive legacy for the deceased. Furthermore, it is also important for clinicians to note the possible grieving individuals who experience suicidal thoughts in the later months. In these situations, cognitive-behavioral therapy and psychodynamic therapy are recommended (Schechter et al., 2019).

Another noteworthy finding is that the grieving parents must be subjected to psychoeducation. This will assist them in comprehending the implications of grief for their physical health. They may also gain insights into how to physically care for their bodies while grieving. Psychoeducation is also recommended for grieving individuals in order to recognize and differentiate between beneficial and unbeneficial coping mechanisms. They can also reflect and evaluate its effects on their grieving. Then, finally, they can explore and develop new coping mechanisms that can replace the unbeneficial ones.

Likewise, parents occasionally experience feelings of guilt and regret. They accepted their shortcomings in their parenting roles in the past. Hence, forgiveness therapy is recommended. This modality will help them uncover the depth of their overwhelming emotions, obtain commitment to forgive, and work on being forgiven by others and themselves.

Also, parents experience disruption in their family. Some parents experience blaming in their families, and that adds complications to their grieving. Mental health professionals must highlight the disruption and its impact on the family structure. Involving other family members in counseling or family therapy may be of great assistance to the grieving parents.

There is no fixed timeline for grieving or remembering a departed child. Hence, mental health practitioners should also examine the remembering theme. Hence, mental health practitioners should also examine the remembering theme.

On the positive side, this study found favorable changes among the grieving parents. In spite of the extreme negative emotional and mental responses, they show positive changes or posttraumatic growth. Our study thus supports and extends the concept of posttraumatic growth (Tedeshi and Calhoun, 2004). The grieving parents displayed positive reactions like improvement in 
interpersonal relationships, change in values in life, sharing insights, spiritual flourishing, and life appreciation identical to those studies of Lee et al. (2017), Martineková and Klatt (2017), Dansart (2016), and Moore et al. (2015).

Thus, in two years, there is a possibility that grieving parents will experience personal improvement. It is also important to note that the positive changes experienced by the grieving parents were appropriate coping mechanisms in an attempt to recover from grief. Improved interpersonal relationships, reconstructed perspective on the meaning of life and the inevitability of death, better relationships with family, strengthened belief in higher beings, and increased willingness to be a witness and share their learning and experience with others are examples of coping mechanisms. One point of caution is that the traumatic loss of a child should not be perceived as a positive event (Lee, 2017). Grieving parents labeled the traumatic loss as one of the worst things that happened in their lives. Death is not avoidable, but the reason for death should not occur. Thus, personal growth is anchored on coping positively with a traumatic loss.

The findings of the study are limited and not generalizable to the population of traumatic loss survivors. However, it conveyed important implications for professional helpers in the field of psychotraumatology. So, in the knowledge of the researchers, this is the first in the Philippines.

\section{5 | Conclusions and Recommendations}

The purpose of this study was to capture the essence of grieving through the lenses of parents who had experienced the traumatic death of a child in Bataan's municipalities. Additionally, it sought to provide in-depth and precise information on this particular occurrence. Four themes emerged: hurting, coping, growing, and remembering. "Hurting" is solely comprised of negative effects of the traumatic loss on the parents' behavior, emotions, physical well-being, social life, and cognition. The "coping" theme is not completely positive in nature. The grieving parents conveyed a combination of positive (e.g., spending time with friends, diverting thoughts, and discovering new interests) and negative coping mechanisms (e.g., overuse of social media, blaming, and moving against others). The growing theme showed the posttraumatic growth side of the parents. It proves that personal transformation is possible in spite of one of the most devastating events in life. Remembering describes how the grieving parents are preoccupied with the memories of their deceased child and is usually categorized as presence (memories of their deceased child when they are still alive) or absence (during the traumatic loss). It will serve as additional knowledge in the fields of psychotraumatology, thanatology, positive psychology, and suicidology in the Philippines. Indeed, this paper proves that a survivor can not just experience the adverse effects of traumatic loss but can also gain positive transformations.

Essentially, the findings revealed important information that will be useful in future research. It is primarily the suicidal ideation experienced by grieving parents in the first few weeks after the loss. This is a critical stage that could lead to a successful suicide attempt. As a result, a qualitative method, specifically a grounded theory design, can denote the stages of suicide during the first few weeks after the loss. It is also strongly advised to develop a brief psychological intervention. Future researchers should investigate the grief experienced by parents as a result of unexpected loss during the pandemic. They know that the pandemic restricts their coping options and aggravates their grieving process by adding anxiety, stress, and fear. A pandemic is additional adversity that affects both their mental and physical health. To the best of our knowledge, parenting actualizations under the growing theme have not been thoroughly researched. This subtheme is related to posttraumatic growth, which is worth investigating and can serve as a foundation for implementing social support programs centered on parenting and grieving. Finally, the final theme, remembering, should be considered for future research. This can generate articles about rituals, activities, and modes to assist parents in navigating their emotions and thoughts about the loss.

\section{References}

Bray, P. (2013, September). Bereavement and Transformation: A Psycho-spiritual and Post-traumatic Growth Perspective. Journal of Religion and Health, 52(3), 890-903. Retrieved 2022-03-08, from http://link. springer .com/10.1007/ s10943-011-9539-8 doi: 10.1007/s10943-011-9539-8

Breen, L. (2006, January). Silenced voices: Experiences of grief following road traffic crashes in Western Australia. Theses: Doctorates and Masters. Retrieved from https://ro.ecu.edu.au/theses/9

Brysiewicz, P. (2007, December). The lived experience of losing a loved one to a sudden death in KwaZulu-Natal, South Africa: Losing a loved one to a sudden death. Journal of Clinical Nursing, 17(2), 224-231. Retrieved 2022-03-08, from https:// onlinelibrary.wiley.com/doi/10.1111/j.1365-2702.2007.01972.x doi: 10.1111/j.1365-2702.2007.01972.x 
Cao, X., Yang, C., \& Wang, D. (2020, March). The Impact on Mental Health of Losing an Only Child and the Influence of Social Support and Resilience. OMEGA - Journal of Death and Dying, 80(4), 666-684. Retrieved 2022-03-08, from http://journals.sagepub.com/doi/10.1177/0030222818755284 doi: 10.1177/0030222818755284

Castelli Dransart, D. A. (2013, March). From Sense-Making to Meaning-Making: Understanding and Supporting Survivors of Suicide. British Journal of Social Work, 43(2), 317-335. Retrieved 2022-03-08, from https://academic.oup.com/ bjsw/article-lookup/doi/10.1093/bjsw/bct026 doi: 10.1093/bjsw/bct026

Corpuz, J. C. G. (2021, June). Beyond death and afterlife: the complicated process of grief in the time of COVID-19. Journal of Public Health, 43(2), e281-e282. Retrieved 2022-03-08, from/https://academic . oup.com/jpubhealth/article/ 43/2/e281/6079613 doi: 10.1093/pubmed/fdaa247

Costa, D. H. d., Njaine, K., \& Schenker, M. (2017, September). Repercussões do homicídio em famílias das vítimas: uma revisão da literatura. Ciência \& Saúde Coletiva, 22(9), 3087-3097. Retrieved 2022-03-08, from http://www . scielo .br/scielo.php?script=sci_arttextŹpid=S1413-81232017002903087Źlng=ptŹtlng=pt doi: 10.1590/141381232017229.18132016

Faschingbauer, T., Zisook, S. \& DeVaul, R. . (1987). The Texas Revised Inventory of Grief. In S. Zisook (Ed.), Biopsychosocial aspects of bereavement. Washington, DC: American Psychiatric Press.

Gamba, F. (2018, January). Coping With Loss: Mapping Digital Rituals for the Expression of Grief. Health Communication, 33(1), 78-84. Retrieved 2022-03-08, from https://www.tandfonline.com/doi/full/10.1080/10410236.2016 .1242038 doi: 10.1080/10410236.2016.1242038

Glad, K. A., Stensland, S., Czajkowski, N. O., Boelen, P. A., \& Dyb, G. (2022, March). The longitudinal association between symptoms of posttraumatic stress and complicated grief: A random intercepts cross-lag analysis. Psychological Trauma: Theory, Research, Practice, and Policy, 14(3), 386-392. Retrieved 2022-03-08, from http://doi.apa.org/getdoi .cfm?doi=10.1037/tra0001087 doi: 10.1037/tra0001087

Henry, S. (2017, January). An Exploration of Resilience and Post-traumatic Growth Following Traumatic Death. Social Work Master's Clinical Research Papers. Retrieved from https://ir.stthomas.edu/ssw_mstrp/753

Keyes, K. M., Pratt, C., Galea, S., McLaughlin, K. A., Koenen, K. C., \& Shear, M. K. (2014, August). The Burden of Loss: Unexpected Death of a Loved One and Psychiatric Disorders Across the Life Course in a National Study. American Journal of Psychiatry, 171(8), 864-871. Retrieved 2022-03-08, from http://psychiatryonline.org/doi/abs/ 10.1176/appi.ajp.2014.13081132 doi: 10.1176/appi.ajp.2014.13081132

Lee, E., Kim, S. w., \& Enright, R. D. (2019, September). Beyond Grief and Survival: Posttraumatic Growth Through Immediate Family Suicide Loss in South Korea. OMEGA - Journal of Death and Dying, 79(4), 414-435. Retrieved 2022-03-08, from http://journals.sagepub.com/doi/10.1177/0030222817724700 doi: 10.1177/0030222817724700

Linley, P. A., \& Joseph, S. (2005, April). The Human Capacity for Growth Through Adversity. American Psychologist, 60(3), 262-264. Retrieved 2022-03-08, from http://doi.apa.org/getdoi.cfm?doi=10.1037/0003-066X.60.3.262b doi: 10.1037/0003-066X.60.3.262b

Martinčeková, L., \& Klatt, J. (2017, August). Mothers' Grief, Forgiveness, and Posttraumatic Growth After the Loss of a Child. OMEGA - Journal of Death and Dying, 75(3), 248-265. Retrieved 2022-03-08, from http://journals . sagepub . com/ doi/10.1177/0030222816652803 doi: $10.1177 / 0030222816652803$

Meyers, A. (2019). A phenomenological study of the lived experiences of counseling students in a co-facilitated experiential group. University of Arkansas.

Michael, C., \& Cooper, M. (2013). Post-traumatic growth following bereavement: A systematic review of the literature. Counselling Psychology Review, 28(4), 18-33.

Mitchell, A. M., Sakraida, T. J., Kim, Y., Bullian, L., \& Chiappetta, L. (2009, February). Depression, Anxiety and Quality of Life in Suicide Survivors: A Comparison of Close and Distant Relationships. Archives of Psychiatric Nursing, 23(1), 210. Retrieved 2022-03-08, from https://linkinghub.elsevier.com/retrieve/pii/S0883941708000496 doi: 10.1016/j.apnu.2008.02.007

Moor, N., \& de Graaf, P. M. (2016, June). Temporary and Long-Term Consequences of Bereavement on Happiness. Journal of Happiness Studies, 17(3), 913-936. Retrieved 2022-03-08, from http://link.springer.com/10.1007/s10902 -015-9624-x doi: 10.1007/s10902-015-9624-x

Moore, M. M., Cerel, J., \& Jobes, D. A. (2015, July). Fruits of Trauma?: Posttraumatic Growth Among Suicide-Bereaved Parents. Crisis, 36(4), 241-248. Retrieved 2022-03-08, from https://econtent.hogrefe.com/doi/10.1027/0227-5910/ a000318 doi: 10.1027/0227-5910/a000318 
Physiological correlates of bereavement and the impact of bereavement interventions. (2012, June). Dialogues in Clinical Neuroscience, 14(2), 129-139. Retrieved 2022-03-08, from https://pubmed.ncbi.nlm.nih.gov/22754285/ doi: 10.31887/DCNS.2012.14.2/tbuckley

Raphael, B. (2006, March). Grieving the death of a child. BMJ, 332(7542), 620-621. Retrieved 2022-03-08, from https:// WWw. bmj.com/lookup/doi/10.1136/bmj.332.7542.620 doi: 10.1136/bmj.332.7542.620

Ross, V., Kõlves, K., Kunde, L., \& De Leo, D. (2018, April). Parents’ Experiences of Suicide-Bereavement: A Qualitative Study at 6 and 12 Months after Loss. International Journal of Environmental Research and Public Health, $15(4), 618$. Retrieved 2022-03-08, from https://www.mdpi.com/1660-4601/15/4/618 doi: 10.3390/ijerph15040618

Schechter, M., Ronningstam, E., Herbstman, B., \& Goldblatt, M. J. (2019, June). Psychotherapy with Suicidal Patients: The Integrative Psychodynamic Approach of the Boston Suicide Study Group. Medicina, 55(6), 303. Retrieved 2022-03-08, from https : //www.mdpi.com/1648-9144/55/6/303 doi: 10.3390/medicina55060303

Shields, C., Russo, K., \& Kavanagh, M. (2019, December). Angels of Courage: The Experiences of Mothers Who Have Been Bereaved by Suicide. OMEGA - Journal of Death and Dying, 80(2), 175-201. Retrieved 2022-03-08, from http:// journals.sagepub.com/doi/10.1177/0030222817725180 doi: 10.1177/0030222817725180

Tedeschi, R. G., \& Calhoun, L. G. (1996). The posttraumatic growth inventory: Measuring the positive legacy of trauma. Journal of Traumatic Stress, 9(3), 455-471. Retrieved 2022-03-08, from https: //onlinelibrary . wiley . com/doi/ 10.1002/jts.2490090305 doi: 10.1002/jts.2490090305

Tedeschi, R. G., \& Calhoun, L. G. (2004, January). TARGET ARTICLE: "Posttraumatic Growth: Conceptual Foundations and Empirical Evidence". Psychological Inquiry, 15(1), 1-18. Retrieved 2022-03-08, from http://www . tandf online .com/doi/abs/10.1207/s15327965pli1501_01 doi: 10.1207/s15327965pli1501_1

Worden, J. W., et al. (2018). Grief counseling and grief therapy: A handbook for the mental health practitioner. springer publishing Company.

How to cite this article: J. Villazor and R. De Guzman, (2022), A Moment that Goes Beyond Silence: Parents' Lived Experiences of Grief Due to Traumatic Loss in Bataan, Philippines, Journal of Education, Management and Development Studies, Vol. 2 No. 1

This work is licensed under a Creative Commons Attribution-NonCommercial-NoDerivatives 4.0 International License 